\title{
Effects of posture and spinal bracing on respiratory function in neuromuscular disease
}

\author{
C M NOBLE-JAMIESON, J Z HECKMATT, V DUBOWITZ, AND M SILVERMAN \\ Department of Paediatrics and Jerry Lewis Muscle Research Centre, Royal Postgraduate Medical School, \\ Hammersmith Hospital, London
}

SUMMARY Effects of posture and spinal bracing on lung function were studied in 40 children with neuromusclar disease, 20 of whom had scoliosis and were non-ambulant. Change from sitting to supine position had little effect on lung function in ambulant children, but caused a significant $12 \%$ reduction in forced vital capacity in a group of 16 non-ambulant children with scoliosis, suggesting diaphragmatic weakness in some. Spinal bracing, using a rigid supporting jacket, resulted in a significant reduction in mean vital capacity of $22 \%$. The degree of impairment in forced vital capacity was proportional to the severity of the scoliosis (as measured by the Cobb's angle), to the amount of correction achieved by the brace, and to the degree of diaphragmatic weakness. Spinal bracing in a child with established severe scoliosis causes appreciable respiratory impairment, and this may explain why it is less likely to be tolerated than early prophylactic bracing.

Muscle disease in children is commonly associated with impairment of respiratory function. ${ }^{1-5}$ One of the earliest changes is reduction in vital capacity due to weakness of the muscles of the chest wall or diaphragm, or both. Later there may be a progressive fall in pulmonary compliance due to microatelectasis, ${ }^{35}$ and reduced compliance of the chest wall due to drooping of the ribs, ${ }^{1}$ muscle fibrosis, and ankylosis of the joints. Scoliosis occurs in many patients with muscle disease, and it contributes to poor lung function by causing a further reduction in vital capacity and ventilation-perfusion mismatch. ${ }^{6}$

Studies in adults with diaphragmatic weakness have shown that the fall in vital capacity from the erect to the supine position is a good indicator of the degree of diaphragmatic weakness. ${ }^{7}$ Similar changes occur in childhood (personal observation), although there are no published data. The effect of spinal bracing on lung function is important because any impairment of lung function due to bracing may affect the child's ability to tolerate the jacket. A previous study of children with idiopathic scoliosis showed that wearing a Milwaukee brace had no effect on vital capacity, but caused significant reduction in maximal voluntary ventilation. ${ }^{8}$ The purpose of the present study was to determine why some children are unable to tolerate spinal bracing. We used the effect of posture as a measure of diaphragmatic function, and studied the effects of spinal bracing on lung function and the relation with the severity of the scoliosis.

\section{Patients and methods}

We studied 40 children with muscle weakness caused by a variety of diseases. They were divided into two groups according to functional status (Table 1). Group 1 comprised 20 ambulant children without scoliosis. The 20 children in group 2 were all non-ambulant and had scoliosis. Sixteen of these children wore a rigid lightweight polypropylene supporting brace to control their scoliosis. The children were accustomed to their brace, which was worn for at least six hours each day, but not at night. The degree of scoliosis was assessed both in and out of the brace by measurements of Cobb's angle using radiographs taken in the sitting position. The functional status of the children was assessed using the Vignos score ${ }^{10}$, with increasing disability indicated on a scale from 1 to 9 . According to this score, a child with a score of over 3 will be unable to climb stairs, and ambulation is lost at a score of over 7 .

The lung function tests used were peak expiratory flow rate, using a Wright Peak Flow meter (Airmed), and spirometry (Ohio Electronic Spirometer) to determine forced vital capacity and forced 
Table 1 Clinical details of subjects in groups 1 (ambulant, no scoliosis) and 2 (non-ambulant plus scoliosis)

\begin{tabular}{|c|c|c|c|c|c|}
\hline & $\begin{array}{l}\text { Duchenne } \\
\text { muscular } \\
\text { dystrophy }\end{array}$ & $\begin{array}{l}\text { Limb } \\
\text { girdle } \\
\text { dystrophy }\end{array}$ & $\begin{array}{l}\text { Congenital } \\
\text { muscular } \\
\text { dystrophy }\end{array}$ & $\begin{array}{l}\text { Spinal } \\
\text { muscular } \\
\text { atrophy }\end{array}$ & Other \\
\hline Group $1(n=20)$ & 5 & 5 & 3 & 2 & 5 \\
\hline $\begin{array}{l}\text { Group } 2 \\
\text { (Posture study: } n=15 \text { ) } \\
\text { (Jacket study: } n=16 \text { ) }\end{array}$ & $\begin{array}{l}10 \\
11\end{array}$ & $\begin{array}{l}0 \\
0\end{array}$ & $\begin{array}{l}2 \\
2\end{array}$ & $\begin{array}{l}3 \\
3\end{array}$ & $\begin{array}{l}0 \\
0\end{array}$ \\
\hline
\end{tabular}

expiratory volume in one second $\left(\mathrm{FEV}_{1}\right)$. The best of three measurements was recorded for each test. None of the children had asthma or recurrent aspiration, and no child had any evidence of respiratory infection within six weeks of testing.

The children in group 1 were tested standing, sitting, and supine. Fifteen of the children in group 2 performed the test, sitting, and supine: they were unable to stand. Sixteen of the group 2 children were tested with and without their spinal jacket in the sitting position. Eleven children in group 2 took part in both the posture and the jacket study.

Predicted normal values were based on armspan. ${ }^{11}$ Changes with posture or with and without jacket were assessed by paired Student's $t$ tests. The mean within patient coefficient of variation of the tests was $4.6 \%$ for forced vital capacity, $7 \cdot 1 \%$ for $\mathrm{FEV}_{1}$, and $6 \cdot 2 \%$ for peak expiratory flow rate.

\section{Results}

Both groups showed the expected impairment in forced vital capacity, $\mathrm{FEV}_{1}$, and peak expiratory flow compared with predicted values (Tables 2,3 , and 4). There was a reduction in forced vital capacity expressed as a percentage of predicted values with increasing functional disability measured by the Vignos score $(r=0 \cdot 64, P<0 \cdot 001$, Fig. 1).

Posture had a significant effect on lung function. In group 1 , mean forced vital capacity fell by $6 \%$

Table 2 Effect of posture on lung function in group 1 (20 ambulant children with no scoliosis). Values are mean $(S D)$ : figures in italics are mean \% predicted

\begin{tabular}{llll}
\hline & $\begin{array}{l}\text { Forced vital } \\
\text { capacity }\end{array}$ & FEV & $\begin{array}{l}\text { Peak } \\
\text { expiratory } \\
\text { flow rate } \\
(1 / \mathrm{min})\end{array}$ \\
\hline Standing & $1.48(0.52)$ & $1.38(0.52)$ & $202(83)$ \\
Supine & 66 & 70 & 73 \\
Sitting & $1.40(0.59)$ & $1.29(0.54)$ & $193(72)$ \\
& 63 & 65 & 70 \\
& $1.50(0.58)^{*}$ & $1.37(0.52)$ & $204(19)^{*}$ \\
& 66 & 68 & 74 \\
\hline
\end{tabular}

${ }^{*}$ Significantly different from supine value $(\mathrm{P}<0.05)$.

$\mathrm{FEV}_{1}=$ forced expiratory volume in one second
Table 3 Effect of posture in group 2 (20 non-ambulant children with scoliosis). Values are mean $(S D)$ : figures in italics are mean $\%$ predicted

\begin{tabular}{llll}
\hline & $\begin{array}{l}\text { Forced vital } \\
\text { capacity }\end{array}$ & FEV & $\begin{array}{l}\text { Peak } \\
\text { expiratory } \\
\text { flow rate } \\
(1 / \mathrm{min})\end{array}$ \\
\hline Sitting & $1 \cdot 10(0.51)$ & $0.98(0.45)$ & $172(72)$ \\
Supine & 42 & 43 & 54 \\
& $0.97(0.48)$ & $0.85(0.44)$ & $148(67)$ \\
& 38 & 39 & 48 \\
& $\mathrm{t}=4.38$ & $\mathrm{t}=3.26$ & $\mathrm{t}=4.57$ \\
$\mathrm{P}<0.001$ & $\mathrm{P}<0.01$ & $\mathrm{P}<0.0101$ \\
\hline
\end{tabular}

$\mathrm{FEV}_{1}=$ forced expiratory volume in one second.

Table 4 Effect of brace in group 2 (16 non-ambulant children with scoliosis). Values are mean (SD): Values in brackets $\%$ predicted

\begin{tabular}{llll}
\hline & $\begin{array}{l}\text { Forced vital } \\
\text { capacity }\end{array}$ & $F E V_{I}$ & $\begin{array}{l}\text { Peak } \\
\text { expiratory } \\
\text { flow rate } \\
(I / \mathrm{min})\end{array}$ \\
\hline Brace on & $0.73(0.43)$ & $0 \cdot 63(0 \cdot 38)$ & $144(68)$ \\
Brace off & 28 & 28 & $5 I$ \\
& $0 \cdot 94(0.58)$ & $0 \cdot 80(0 \cdot 53)$ & $1.58(83)$ \\
& 36 & 36 & 52 \\
$\mathrm{t}=4.11$ & $\mathrm{t}=3.41$ & $\mathrm{t}=1.25$ \\
$\mathrm{P}<0.01$ & $\mathrm{P}<0.01$ & $\mathrm{~ns}$ \\
\hline
\end{tabular}

$\mathrm{FEV}_{1}=$ forced expiratory volume in one second.

from sitting to supine positions $(P<0 \cdot 05$, Table 2$)$, but there were no significant changes in $\mathrm{FEV}_{1}$ or expiratory flow. The children in group 2 , however, showed highly significant impairment in all parameters of lung function from sitting to supine positions $(\mathrm{P}<0 \cdot 01$, Table 3$)$. In four boys with Duchenne muscular dystrophy, forced vital capacity fell by more than $20 \%$ from the initial values in the sitting position, with a mean reduction of $12 \%$ for the group 2 as a whole $(\mathrm{P}<0 \cdot 001)$. Mean FEV , fell by $12 \%$, and mean peak expiratory flow fell by $14 \%$ from sitting to supine positions (Table 3 ).

The effect of spinal bracing on lung function was tested in 16 children in group 2 . Wearing a jacket 


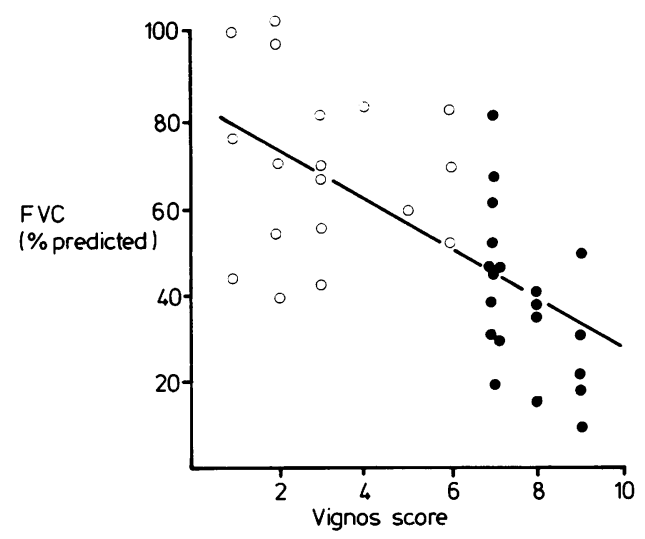

Fig. 1 Relation between Vignos score and forced vital capacity (FVC) (\% of value predicted from arm span).

Open circles group 1, closed circles group 2 patients. $r=0.64, P<0 \cdot(001$.

caused a mean reduction in forced vital capacity of $22 \%(\mathrm{P}<0 \cdot 01$, Table 4$)$, seven patients showing impairment of greater than $25 \%$. The impairment in force vital capacity was related to the angle of scoliosis $(r=0 \cdot 5, P<0.05)$ and to the degree of improvement due to bracing $(r=0 \cdot 5, P<0 \cdot 05$, Fig. 2 ). The two children with the greatest impairment in forced vital capacity as a result of bracing both had severe Duchenne muscular dystrophy. They achieved considerable improvement in Cobb's angle with the brace but unfortunately this was at the cost of considerable restriction in lung volume. Furthermore, of the four boys with Duchenne muscular

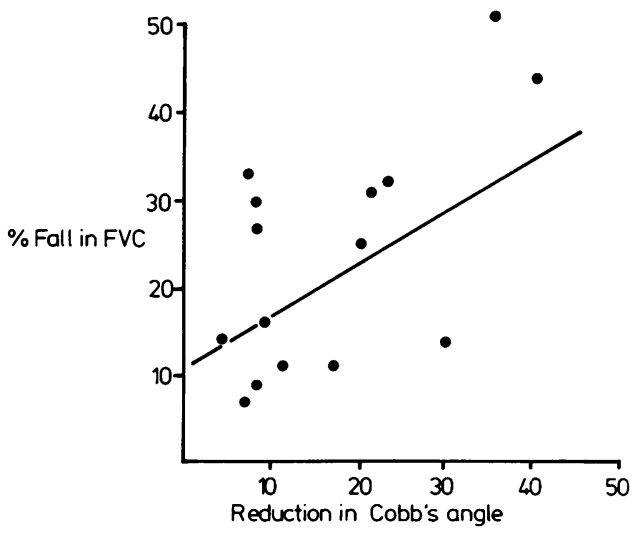

Fig. 2 Relation between reduction in Cobb's angle due to the brace, and the fall in forced vital capacity (FVC) (\% of baseline value) due to the brace.

$r=0.5, P<0.05$. dystrophy who showed the greatest impairment in forced vital capacity when lying supine (suggesting severe diaphragmatic weakness), one was unable to tolerate a brace and the remainder showed severe restriction in forced vital capacity as a result of bracing. Mean $\mathrm{FEV}_{1}$ fell by $21 \%$ as a result of bracing $(P<0.01$, Table 4$)$, but overall there were no significant effects on peak expiratory flow rate: in four patients the peak flow fell by more than $25 \%$ when wearing a jacket, but surprisingly, in three patients the peak flow improved by more than $25 \%$ in the brace, despite significant impairment in forced vital capacity.

\section{Discussion}

We have shown that in severely weak patients, lung function may be significantly impaired in the supine position; furthermore, wearing a rigid supporting jacket for scoliosis causes further restriction in lung volume.

Posture has an effect on lung function in normal adults $^{12}$ with a fall of approximately $5 \%$ from erect to supine but we have been unable to find any published data for children. Twenty normal schoolchildren aged 6 to 17 years, however, studied at this hospital (Reynolds, 1979, unpublished data) showed a mean reduction in forced vital capacity of $4.8 \%$ from standing to supine positions $(\mathrm{P}<0 \cdot 02)$. All of the children in group 1 had definite muscle weakness, but the $6 \%$ fall in forced vital capacity from sitting to supine hardly differs from the normal population. The children in group 2 , however, were weaker and had the additional disadvantage of scoliosis. In this group the mean fall in forced vital capacity from sitting to supine was $12 \%$. Four boys with Duchenne muscular dystrophy showed reductions from 22 to $29 \%$, suggesting a significant degree of diaphragmatic weakness. Three of these boys showed severe restriction in forced vital capacity as a result of bracing, and the fourth was completely unable to tolerate a brace.

It was surprising to find that three of the children with substantial impairment in forced vital capacity when supine actually improved their peak expiratory flow by 26 to $63 \%$ when wearing a brace. It is possible that these children might have learned to make use of the splinting effect of the brace on the abdomen and could thus improve their peak flow and also improve their capacity to clear secretions or cough.

Spinal bracing using rigid jackets is an important stage in the management of scoliosis, since there is rapid progression if left untreated, particularly in children with muscle weakness. Children with severe scoliosis, however, are usually reluctant to 
wear a brace. We have shown that spinal bracing for severe scoliosis results in a considerable reduction in forced vital capacity, and this may contribute to difficulty in tolerating the brace, particularly as lung function is already seriously impaired by weakness of the intercostal muscles and diaphragm. The reduction in forced vital capacity due to bracing was proportional to the angle of the scoliosis and the degree of correction achieved by the brace, and this would explain why early prophylactic bracing is more likely to be tolerated, since the jacket has little effect on lung function when the scoliosis is mild.

Children with muscle disease often need spinal surgery despite bracing. Operations such as the Dwyer procedure or Harrington instrumentation may require prolonged immobilisation in the supine position, which would be extremely hazardous in a child with severe diaphragmatic weakness. In such cases the newer Luque procedure ${ }^{13}$ may be preferable, since earlier mobilisation is possible after surgery. Regular assessment of lung function using simple spirometry can give valuable information about the effects of bracing and about diaphragmatic function. The results may help to predict which children will be able to tolerate spinal bracing, and to decide on the timing of spinal surgery.

We thank Dr Debbic Hodes and Miss Caroline Dixon for their help with this project.

\section{References}

${ }^{1}$ Hapke EJ, Meek JC, Jacobs J. Pulmonary function in progres- sive muscular dystrophy. Chest 1972;61:41-7.

2 Burke SS, Grove NM, Houser CR, Johnson DM. Respiratory aspects of pseudohypertrophic muscular dystrophy. Am J Dis Child 1971;121:230-4

${ }^{3}$ Gibson GJ, Pride NB, Newsom Davis N, Loh LC. Pulmonary mechanisms in patients with respiratory muscle weakness. Am Rev Respir Dis 1977;115:389-95.

${ }^{4}$ Dubowitz V. Muscle disease in childhood. Philadelphia: Saunders, 1978:253-4.

${ }^{5}$ de Troyer A, Borenstein S, Cordier R. Analysis of lung volume restriction in patients with respiratory muscle weakness. Thorax 1980:35:603-10.

${ }^{6}$ Dollery CT, Gillam PMS, Hugh-Jones P, Zorab PA. Regional lung function in kyphoscoliosis. Thorax 1965;20:175-81.

${ }^{7}$ Newsom Davis J, Goldman M, Loh L, Casson M. Diaphragm function and alveolar hypoventilation. $Q J$ Med 1976;XLV: $87-100$.

${ }^{8}$ Sevastikoglou JA, Linderholm H, Lindgren U. Effect of the Milwaukee brace on vital and ventilatory capacity of scoliotic patients. Acta Orthop Scand 1976;47:540-5.

${ }^{9}$ Cobb JR. Outline for the study of scoliosis, instructional course lectures. American Academy of Orthopaedic Surgeons 1948:5:261-75

10 Vignos PJ, Spencer GE, Archibald KC. Management of progressive muscular dystrophy of childhood. JAMA 1963;184:89-110.

" Godfrey F, Kamburoff PL, Nairn JR. Spirometry, lung volumes and airway resistance in normal children aged 5 to 18 years. $\mathrm{Br} J$ Dis Chest 1970;64:15-24.

12 Hamilton WF, Morgan AB. Mechanism of postural reduction in vital capacity in relation to orthopnea and storage of blood in the lungs. Am J Physiol 1932;99:526-33.

${ }^{13}$ Luque ER. Segmental spinal instrumentation for correction of scoliosis. Clin Orthop 1982;163:192-8.

Correspondence to $\mathrm{Dr} \mathrm{C}$ M Noble Jamieson, Department of Paediatrics and Neonatal Medicine, Hammersmith Hospital, London W12 0HS.

Received 26 September 1985 